\title{
A EDUCAÇÃO COMO PREPARAÇÃO PARA O SENTIDO DE COMUNIDADE EM MARTIN BUBER
}

Rudinei Borges dos Santos ${ }^{1}$

Resumo: Este artigo tem por objetivo apresentar as proposições de Martin Buber (1878-1965) no campo da Filosofia da Educação mediante a análise de um texto específico de sua vasta produção, a saber: uma conferência realizada em 1929, intitulada Educação para a comunidade, que integra o livro Sobre comunidade, uma coletânea de textos de Buber organizada por Marcelo Dascal e Oscar Zimmermann.

Palavras-chave: Educação; Comunidade; Princípio dialógico.

Abstract: This article aims to present the propositions of Martin Buber (1878-1965) in the field of Philosophy of Education through the analysis of a specific text from his vast production, namely: a conference held in 1929, entitled Education for the community, which is part of the book About community, a collection of texts by Buber organized by Marcelo Dascal and Oscar Zimmermann.

Keywords: Education; Community; Dialogical principle.

\footnotetext{
${ }^{1}$ Doutorando e Mestre em Educação pela Universidade de São Paulo (USP), com graduação em Licenciatura Plena em Filosofia. Currículo Lattes: http://lattes.cnpq.br/0477323246228020.
} 


\section{Introdução}

Creio que educação é relação (...). Por esse termo relação entendo relação direta, isenta de propósitos, cujo fim é ela mesma, isto é, a capacidade para tal relação com as pessoas com as quais se convive. É para isso que a educação para a comunidade educa (BUBER, 1987, p. 93).

A perspectiva educacional em Martin Buber (1878-1965) desenvolve-se alicerçada nos princípios apresentados desde a publicação de sua obra mais importante, Eu e tu (1923). Isso significa uma impossibilidade de pensar a educação, assim como Buber a concerne, sem que se ponha em questão o princípio dialógico, a relação, o pôr-se face a face com o outro (Tu) e a comunidade. É exatamente na comunidade, e com a comunidade, que a relação acontece, sem isso é dispensável educar.

Neste exame, realizaremos o estudo das proposições educacionais de Buber mediante a análise de um texto específico de sua vasta produção filosófica e pedagógica, a saber: uma conferência realizada em 1929, intitulada Educação para a Comunidade, ${ }^{2}$ que integra o livro Sobre comunidade ${ }^{3}$ uma coletânea de textos de Buber organizada por Marcelo Dascal e Oscar Zimmermann.

No posfácio da edição brasileira, nota-se com destaque, nas palavras de Newton Aquiles von Zuben, que a ênfase sempre atribuída, por meio de toda a obra de Buber, à compreensão da comunidade, de um determinado tipo de vida em comum, reflete uma dimensão relevante de sua filosofia social que é a afirmação da condição relacional do ser humano. Escritos em diversas etapas de sua vida, os textos reunidos em Sobre comunidade podem ser lidos à luz das considerações de Buber consagradas ao princípio dialógico apresentado em Eu e Tu (ZUBEN, 1987, p. 129).

Sabe-se que a transformação da vida social do ser humano representou uma das preocupações centrais do pensamento buberiano. O protesto lançado por ele contra a despersonalização ou contra a "coisificação", a que foi submetido o homem moderno por meio da supremacia do Eu-Isso em detrimento da autêntica relação, serve de certo modo, como pano de fundo para a tentativa de transformação para a verdadeira comunidade.

Buber credita o amadurecimento do problema antropológico a dois fatores: o primeiro, cujo caráter sociológico é preponderante, diz respeito à progressiva decomposição de antigas formas orgânicas de convivência direta entre as pessoas. Eram comunidades que,

\footnotetext{
${ }^{2}$ Palestra proferida em 6 de abril de 1929.

${ }^{3}$ Cf. BUBER, Martin. Sobre comunidade. Tradução de Newton Aquiles von Zuben. São Paulo: Perspectiva, 1987
} 
quantitativamente, não deveriam ser mais amplas que o necessário para reunir as pessoas em relação direta, e nas quais, elas entravam pelo nascimento e viam, na sua pertença a elas, não o resultado de um livre acordo com o outro, mas uma obra do destino e uma tradição vital. Tais comunidades eram representadas pela família, pelo companheirismo, pela comuna aldeã ou urbana. A decomposição dessas comunidades foi o preço pago para o nascimento da sociedade burguesa (ZUBEN, 1987, p. 130).

O segundo fator é o agravamento da solidão do ser humano. A este ser moderno, que havia perdido o sentimento de habitar o universo, as formas orgânicas de comunidade ofereciam uma sentença de "estar-em-casa", uma segurança sociológica que o preservava do sentimento de abandono total (BUBER, 2005, p. 82). Essas formas orgânicas antigas, embora conservassem características exteriores, dissolviam-se internamente e perdiam progressivamente seu sentido e seu poder interior. As novas formas sociais que substituíram as antigas e tentaram recuperar o lugar da pessoa humana nas relações sociais, como a associação, o sindicato, ou o partido, não conseguiram restabelecer a segurança perdida. A solidão crescente só foi abafada e reprimida.

A sociedade ensaia um esgotamento da espontaneidade da pessoa, da ação dialogal na sua emergência, tornando as pessoas supérfluas ou "egóticas" (BUBER, 1977, p. 73), peças de um mecanismo. Disso resulta a negação da vontade, da decisão, da responsabilidade do agir em comum, recíproco, do diálogo.

Contra esse esfacelamento da pessoa pelo mecanismo de interesses (coletivismo) não se deve procurar o remédio, avalia von Zuben, em um igualmente fictício ensimesmamento no privado, um mergulho no próprio eu, mas de lado a lado da saída, da aparência desse eu no espaço público do entre-dois (ZUBEN, 1987, p. 132).

A verdadeira comunidade não nasce do fato de que as pessoas têm sentimentos umas para com as outras (embora ela não possa, na verdade, nascer sem isso); ela nasce de duas coisas: do fato de estarem todos em relação viva e mútua com um centro vivo e estarem unidos uns aos outros em uma relação viva e recíproca... A comunidade edifica-se sobre a relação viva e recíproca, todavia o verdadeiro construtor é o centro vivo e ativo (BUBER, 1977, p. 53).

O início de um espaço político acontece na ação dialógica. A descoberta do comum (público) passa pela revolução do pensamento do comunitário que, mais do que pelo meio de uma previsão organicista, emerge pela prudência do juízo posto em prática na ideia de linha de demarcação, tal como a concebe Buber. 
Buber rejeita ao mesmo tempo o individualismo atomístico e o coletivismo totalitário, em sua afirmação da comunidade autêntica, a que se manifesta na relação direta entre os seres humanos. Com isso, aponta a visão de uma comunidade orgânica, uma comunidade de comunidades construída por pequenas comunidades.

Ao afirmar enfaticamente que o desígnio da comunidade é a própria comunidade, está negando qualquer possibilidade de se reduzir o comum, a existência plural, a uma unidade. A comunidade é uma pluralidade que deve ser preservada da subordinação a qualquer aparelho unificador.

Nessa unidade, as pessoas veem assegurada a singularidade de sua condição humana. Na comunidade a pessoa não é reduzida à mera função de uma massa, a um papel numa classe. A pluralidade, condição necessária para a comunidade, tem dupla característica: igualdade e distinção. Igualdade não no sentido de igualdade de nascimento, mas igualdade de condição de existência comum no espaço comum da comunidade. Essa igualdade não é uma redução ao idêntico, ao invariável, mas paridade fundamental que autoriza a participação da palavra que nos distingue do outro manifestando-nos nossa identidade própria. $\mathrm{O}$ Eu-Tu não autoriza a fusão no outro ou a absorção na realidade do outro, mas é a relação recíproca e total com o outro.

A comunidade exige o espaço comum da ação recíproca, espaço que não é geométrico ou uma estrutura social, mas o lugar que dá origem, princípio (archein no duplo sentido de colocar em movimento e sustentar) da relação. O "entre-dois" é o espaço ontológico cuja característica é reunir sem fundir uma na outra - igualdade e distinção. É o "entre-dois" que autoriza o intervalo que congrega a distância. O "entre-dois" funda o espaço público como lugar comum que permite não o "estar-diante-do-outro", mas o face a face direto que interdiz o anonimato. (...) Se o anonimato prevalecer, a comunidade se degenerará em dispersão tirânica (onde é contestada e negada toda personalização), ou então em concentração totalitária que esmaga os indivíduos, mas uns contra os outros e os reduz a um conglomerado, massa amorfa na qual toda responsabilidade desaparece. A massa, negativo de povo, consiste numa totalidade de indiferença em que nenhum elo comum, seja social ou político, une os elementos desse agregado para fazer dele uma comunidade. Ao contrário, o que está no princípio da massa é a atomização extrema de indivíduos não como formação social, mas como socialidades amorfas. Privados do "intervalo", do "entre-dois", fundador do vínculo dialógico, os indivíduos que compõem a massa não são agregados senão por seu isolamento mútuo. Experimentam assim a desolação como experiência de absoluta "não-pertença" (ZUBEN, 1987, p. 133-134).

Como emerge a comunidade? Qual o seu fundamento? A relação como ação dual, recíproca no "entre-dois", é seu único antecedente. Há, em Buber, uma metafísica do inaugural: o começo no sentido de ascendência, e não no sentido de início cronológico, é seu 
princípio norteador. Essa ação não conhece as categorias de fins e meios. A comunidade é o seu próprio fim, assim como a finalidade da relação Eu-Tu é a própria relação. Quando pessoas se inter-relacionam no diálogo e todos estão integrados como centro ativo, aí surge a comunidade. A ação recíproca que se instaura no diálogo exigirá, para a total efetivação da comunidade que cada pessoa, que cada membro desta comunidade confirme o outro. A confirmação do outro naquilo que ele é será o cimento social para a convivência na pluralidade. Graças à confirmação será possível a identidade pessoal e a distinção entre os membros. Esta confirmação não será buscada no próprio indivíduo, numa atitude de autonomia, ou por meio de sua inserção no coletivo. Essas duas formas de confirmação são ilusórias. No nível da vida social aparecem como individualismo ou coletivismo. Contra ambos, Buber propõe o surgimento de uma comunidade orgânica na qual a confirmação é um processo eminentemente recíproco de várias pessoas que interagem. É no encontro “entredois" que se manifestará a força da comunidade. Quanto à implantação da comunidade, Buber permanece otimista, apesar da consciência de crise do mundo de seu tempo, analisa von Zuben (1987, p. 134-135). É, nesse sentido, que, para pensar educação em Buber é necessário compreender o sentido de comunidade no encontro "entre-dois", na relação Eu-Tu.

Quem quer que deseje obter comunidade deve educar para a comunidade. E isso requer uma concepção inteiramente nova de educação, argumenta Buber. Esse é o tópico central da conferência de 1929. Novamente, ressaltam Dascal e Zimmermann (1987, p. 1331), esse é apenas um pequeno exemplo do gigantesco esforço investido por Buber (na época e posteriormente), não somente na elaboração de uma nova perspectiva educacional, mas também na implementação de suas concepções ao nível de escola pública, da secundária, da universidade, e também no seu projeto de educação para adultos.

No concernente à comunidade, Buber denuncia as definições em voga de educação comunitária, concebida em termos de um adestramento do indivíduo para cumprir seu papel na sociedade, no estado, no partido, ou em qualquer outra forma de associação social com que venha a se deparar. Para Buber, isso nada tem a ver com o seu próprio conceito de comunidade, e conduz na verdade à sua antítese. A educação para comunidade, no sentido buberiano, requer uma relação genuína Eu-Tu entre discípulo e discípulo, como também entre mestre e discípulo, e isso só pode ser obtido não por meio de uma teorização ou pregação, mas pela transformação da própria comunidade num verdadeiro espaço de comunitariedade (DASCAL, M.; ZIMMERMANN, O., 1987, p. 28). 


\title{
Crítica às associações mecanizadas e à ideia de comunidade como aliança
}

Buber critica duramente a ideia de educação comunitária que consiste em qualificar ou equipar as pessoas em desenvolvimento com a capacidade de se orientarem diante de grandes objetivos, tais como, sociedade, Estado, partido, associações, nos quais a vida irá situá-las.

Essa ideia de educação comunitária fará com que a pessoa se torne um membro útil, produtivo, no seio dessas diversas modalidades de associações sociais e políticas.

Que ele não seja simples roda que só gire em torno de seu eixo, mas uma pessoa, uma roda equipada com dentes e, assim, esteja apta a engrenar em outras rodas deste enorme aparato e seja capaz de participar deste imenso e complicado movimento global (BUBER, 1987, p. 82).

No entanto, isto tem pouco a ver com comunidade.

\begin{abstract}
Não posso convencer-me de que as associações, sobre as quais se fala aqui, a saber, o Estado atual, a sociedade atual etc., têm a ver com a comunidade. Ou, em outros termos, há redutos de comunidades no Estado, na sociedade etc. E mais, em nossos dias a vida humana ainda não se tornou um mecanismo de modo a não existir comunidade em lugar algum, nem mesmo em todas essas assim denominadas imensas associações mecanizadas - embora não seja um termo feliz - (eu diria antes associações objetivadas). Porém, na realidade, se procurarmos uma autêntica vida comunitária nestas grandes associações, não a encontraríamos em nenhuma delas (BUBER, 1987, p. 82-83).
\end{abstract}

Assim, na conferência de 1929, Buber assevera que é difícil explicar o que ele denomina comunidade, cujos resquícios ainda perduram nas comunidades contemporâneas. $\mathrm{Na}$ procura por tornar compreensíveis as suas proposições sobre comunidade e, assim, aproximar-se de uma ideia de educação comunitária utiliza de conceitos da sociologia moderna, em particular dos estudos de Toennies. ${ }^{4}$

Para Buber (1987, p. 83), a obra de Toennies ${ }^{5}$ opõe sociedade à comunidade quando afirma que a sociedade é uma associação de pessoas unidas por um determinado propósito, que possuem interesse comum e se congregam a fim de servirem a esses interesses comuns e atingirem este fim. Trata-se, então, de uma convenção fundada sobre uma decisão. Por outro lado, comunidade é a união de pessoas ligadas pela própria essência e pela própria vontade essencial, uma união que é resultado de um processo natural e não algo imposto; é baseado

\footnotetext{
${ }^{4}$ No final do século XIX e início do XX a obra de Toennies era leitura obrigatória. Buber faz referência a uma obra clássica de Toennies, a saber: Comunidade e Sociedade.

${ }^{5}$ Toennies apresentou uma análise de dois tipos de sociedade, a tradicional e a liberal e contratual; ao mesmo tempo desenvolveu uma psicologia social que investigou os efeitos das instituições em que vivem as pessoas sobre sua própria autoconsciência. Em que medida as estruturas em que vivem os homens afetam a consciência de cada um de seus valores e sentimentos. Sem dúvida a sua tipologia sócio-psicológica é ainda um arsenal para os críticos da sociedade moderna (ZUBEN, 1987, p. 131).
} 
em sua origem comum, costumes, propriedades etc. De fato, o ser humano nasce na comunidade. Ela é sua condição. Ele vive, respira nela, ela o sustenta. A sociedade é algo que, por assim dizer, ele reconhece sem cessar e aceita como algo essencial para a orientação de sua vida, para os fins que ele se propõe e deseja atingir. Por isso, ele se insere na sociedade.

Este confronto entre os conceitos de sociedade e comunidade funda-se, como se pode ver, à primeira vista, numa perspectiva histórica. O que se denomina aqui comunidade é uma condição social primitiva. São, de fato, categorias históricas que se sucedem umas às outras no desenvolvimento da humanidade, no desenvolvimento das culturas individuais. Porém, a partir dessa perspectiva, não é possível definir o que se entende, na vida moderna, por comunidade.

Esta primitiva comunidade de comunhão de costumes, de propriedades etc., não abrange o que conhecemos por comunidade. Alguns filósofos modernos (Herman Schmalembach $)^{6}$ tentaram completar essa concepção, acrescentando um terceiro conceito aos dois anteriores - sociedade e comunidade - a saber, o conceito de aliança.

Para Schmalembach, avalia Buber (1987, p. 84), comunidade é aquilo que se tornou comum, é onde o ser humano nasce, aquilo que, por assim dizer, se relaciona com seu subconsciente. Não é resultado de sua escolha e decisão conscientes; Schmalembach denomina de "aliança" aquilo que, ao invés de conduzir à formação de sociedade, conduz à autêntica união orgânica (de pessoas), à formação de um verdadeiro círculo. Schmalembach, todavia, não compreendeu que a sociedade moderna, de fato, não se levantou contra a comunidade primitiva, e que, de outra parte, não contém o tipo de "comunitariedade" que pode ser concebido e aspirado pela vida moderna e ultrapassa os limites da comunidade primitiva.

Com isso, Buber entende ser a aliança algo que não engloba toda a vida orgânica do ser humano - e isso não por mera causalidade, mas pela sua própria essência. Ao contrário, é algo que acompanha a vida orgânica e natural do ser humano ou enfatiza somente uma dimensão dela. Se a aliança é de caráter político, inclui pessoas que aspiram alguma mudança; ou, se é de caráter religioso - não, porém, uma parte da vida, no sentido moderno de "religioso" -, ela é um tipo de consagração de algumas horas que seria, por isso, separada da vida e que assim transcenderia a vida cotidiana. A aliança é algo que não engloba a

\footnotetext{
${ }^{6}$ Herman Schmalembach (1885-1950). Suas principais obras foram: Leibniz (1921), Die Kantische Philosophie und Religion (1926) eDas Ethos und die Idee des Erkennens (1933).
} 
cotidianidade e a regularidade da vida. Ela pretende organizar as maiores aspirações do ser humano - tomando-se isso não pejorativamente.

É típico da "aliança" que as pessoas saiam de suas casas para irem ao local onde pertencem à aliança; afastam-se de suas ligações com a regularidade da vida a fim de atingirem a consagração. A aliança tem duplo fundamento. Não é algo jamais que engloba toda a vida natural do ser humano: a vida doméstica, a vida na rua, no trabalho. Engloba pessoas que se recolhem, se retiram da vida agitada e se associam para essa existência em comum, separada essencialmente daquela vida, tanto num sentido espacial quanto temporal (BUBER, 1987, p. 85).

Ao se referir ao termo comunidade, Buber entende algo que abrange toda a vida, toda a existência natural do ser humano, não excluindo nada dela. "Ou a comunidade é isso, ou, então, deve-se renunciar à ideia da existência de uma comunidade autêntica” (1987, p. 85). Que a comunidade possa ser realizada ou não, depende muito dessa união total. A comunidade que se erige ao lado da vida não é comunidade. Com isso, Buber não tem por objetivo prejudicar, de algum modo, a existência das alianças, mas afirma que todas são somente pressentimento ou antecipação de alianças.

As alianças realizam-se na separação da vida, o que não pode ser realizado aqui e agora na plenitude e no trabalho da vida, ou que é considerado irrealizável. Essa resignação ou esse conhecimento, essa renúncia, esse elemento negativo encontra-se no fundo da "aliança" que constrói um plano sobre o qual será realizado aquilo que não pode ser realizado no plano da vida. A aliança apresenta um modo consolador para se sair da impossibilidade de realização na plenitude da vida vivida, criando experiência de comunidade.

Esta experiência de comunidade, porém, não entra na vida vivida, não preenche todas as fendas e poros, não se estende por toda a parte, para, tão somente, erigir-se como vida, mas é um pacto negativo firmado, um muro erigido: ela é reconhecida como: "até aqui e não adiante". E este "até aqui", se observa atentamente, é o início da verdadeira vida não-patética, da autêntica vida (BUBER, 1987, p. 85).

A partir dessa análise da ideia de comunidade como aliança, Buber faz a seguinte indagação:

Pode existir neste mundo em que vivemos, neste mundo humano, outro tipo de comunidade se não a aliança? Aquela comunidade que engloba tudo não é, na verdade, uma condição primitiva, uma condição de uma diferenciação menos pessoal? Não é uma condição na qual os homens não podem viver realmente em comunidade, porque não estão ainda separados uns dos outros pela 
personificação, como os homens de hoje, e por que eles não se confrontam mutuamente nesta multiplicidade? (1987, p. 86).

Para Buber, as pessoas cresceram na diferenciação da sociedade contemporânea, a partir precisamente de ligações naturais e é, por isso, puro romantismo pretender voltar à comunidade, que, na forma de um englobante de toda a vida, está perdida para nós. Tal questão parece central para Buber: se a comunidade (ignoremos a aliança como associação que não engloba a totalidade da vida) é, de fato, idêntica à sociedade subcomunal. Na realidade, a comunidade, considerada pela sociologia em contraste com a sociedade, é sem dúvida de tipo subcomunal. Diz respeito à comunidade a partir da qual a ordem individualista se desenvolveu como fundamento da sociedade contemporânea.

Buber admite isso, mas anseia assinalar que o desejo de retornar aquém dessa diferenciação da ordem social moderna é uma tendência sem esperança. Tudo depende da possibilidade ou não de um desenvolvimento posterior da comunidade, isto é, se existe não só uma comunidade subsocial, mas também uma comunidade supra-social, vale dizer, se é possível sua realização com os preconceitos e meios da situação e da ordem atual.

\section{A comunidade autêntica}

O sentido de comunidade amparado por Buber não repousa mais sobre o "ter em comum", sobre propriedades objetivas, como costumes, ligação legal ou outra característica da comunidade primitiva. Ao contrário, fundamenta-se em um caráter muito peculiar de “comunialidade". Não se tratando, portanto, de um "estar-com” estático, mas dinâmico. Nem diz respeito a seres humanos feitos, formados e ordenados de modo semelhante, mas sim sobre pessoas que, formadas e ordenadas diferentemente, mantêm uma autêntica relação entre si.

Partindo dessa diferença como essência da ordem atual, Buber indaga: "Como pode haver comunidade que não seja dinâmica, de modo que a comunidade seja algo que aconteça entre homens, entre Eu e Tu?" (1987, p. 87).

Não obstante, se há a pretensão de inferir um autêntico conceito de comunidade a partir da situação do ser humano em seu tempo, então comunidade significa, aqui e agora, multiplicidade de pessoas, sendo que sempre seja possível para qualquer um, que a ela pertença, estabelecer relações autênticas, totais e sem finalidades, de modo que exista tal relação entre todos os membros. 


\section{a) A imediaticidade}

Em Buber, o importante são as centelhas, o acontecimento verdadeiro. Porém, o estatuto, a estrutura da multiplicidade de pessoas, deve ser tal que nada reprima esse caráter de relação ou que a torne impossível.

Assim, em sua exposição, Buber reafirma (1987, p. 87), sempre que possível, que a relação deve ser imediata, que as pessoas se encontrem mutuamente na ação mútua, sem que algo de pessoal ou objetivo se interponha entre elas, que se relacionem não pelo fato de possuírem algo em comum (interesses, negócio, trabalho ou qualquer ligação prática ou uma realização), mas, ao contrário, que se relacionem imediatamente sem intermediários. As centelhas da relação cintilam daqui e dali, de pessoa a pessoa. Nisso concerne a imediaticidade.

\section{b) A totalidade da relação}

O segundo ponto fundante de uma perspectiva buberiana de comunidade autêntica, responde à totalidade da relação. Isso significa que a relação de um ser humano com o seu semelhante não envolve somente uma parte de seu ser, quando os vários domínios da vida espiritual são separados, cada um com sua própria lei, sua própria estrutura, sua própria contabilidade.

Há determinadas relações espirituais entre os seres humanos com caráter muito peculiares: algumas pessoas se encontram, certa noite, para discutir assuntos de maiores interesses para elas como se tivessem realmente algo a ver umas com as outras, sem que, na realidade, o tenham. Nenhuma delas se prendeu por algum compromisso, uma com a outra.

Essa divisão do ser humano em conjuntos de esferas atinge também a realização do interhumano. A totalidade da relação é parte importante da comunidade. A pessoa encontra-se com as outras com todas as suas qualidades, habilidades, possibilidades e entre elas algo acontece, nada mais. Buber (1987, p. 88) não se refere a coisas extraordinárias, podendo ser qualquer evento - mesmo algo altamente negativo - que ocorra entre as pessoas, um evento real, imediato, do qual participam com a totalidade de seu ser.

\section{c) Que o outro (Tu) não seja um meio (Isso)}

O terceiro ponto fundante de uma perspectiva buberiana de comunidade autêntica alicerça-se no princípio de que o ser humano não seja um meio para outros conseguirem um 
fim. Que um não use o outro, mas que o considere um ser vivo que está diante de si, um ser para o qual Eu estou aqui, do mesmo modo que ele (Tu) está aqui para mim (Eu). Não havendo nenhuma possibilidade de coisificação do outro - atitude que, em si mesma, não considera a possibilidade do diálogo. Todo o pensamento educacional de Buber assenta-se nessa denúncia e recusa da ação que compreende o outro como um meio.

\section{Educação e comunidade autêntica}

Em Buber, "a educação é a preparação para o sentido de comunidade, na vida pessoal e com a vida pessoal" (1987, p. 89). Com efeito, algo parece resultar dessa acepção: a educação para a comunidade não pode ser teórica, só pode ocorrer por meio da comunidade. O que educa e quem educa é - em última análise - o espontâneo.

O melhor exemplo de educação é a natureza. Ela educa através da luz, do ar, da floresta, dos animais e tudo o que se pode experenciar. Na cidade isto ocorre, mas em menor grau. Assim é educado o homem adulto. Não imaginamos o quanto uma criança é educada pela luz. Eu próprio observei isso em crianças. A criança é a que está menos consciente disso, e os adultos que cuidam das crianças, também sabem, infelizmente, muito pouco a respeito do efeito inconsciente do ambiente natural. O que educa mais? (BUBER, 1987, p. 90).

Pode-se afirmar que a comunidade educa na medida em que ela está presente. Pode-se também afirmar: o indivíduo educa, na medida em que está presente. Porém, Buber considera um dos principais caminhos de sua proposição educacional, o acontecimento espontâneo como o meio mais característico de uma educação comunitária.

Considerem o seguinte: uma pessoa chega e as crianças estão sentadas para serem educadas; então, pensam os senhores, que a seguinte situação não penetra a mente das crianças: "Agora vamos ser educados"!?... Consideremos novamente a influência do professor sobre os alunos. Como o professor exerce realmente influência sobre o aluno? Na medida em que não existir esta resistência, na medida em que não houver entre ele e o aluno esta seguinte situação: "Ah, agora vamos ser educados!". Em outras palavras, quando as relações entre professores e alunos forem espontâneas e estes não o saibam e nem o percebam. Quando ele educa, o faz com sua existência pessoal, e se ele se acha incapaz de ensinar assim, é recomendável que mude de profissão (BUBER, 1987, p. 90).

Educar para a comunidade só é possível na medida em que existe comunidade que educa para a comunidade. As pessoas são educadas pela simples vida comunitária na qual nasceram e cresceram. Daí pode-se perguntar: que possibilidades são reconhecidas à escola para esse tipo de educação? 
Pode-se afirmar que as escolas comunitárias são essencialmente comunidades. E há, em sua análise, um tipo de escola que apresenta um aspecto essencialmente favorável: a escola rural. Apesar da degradação do campesinato, avalia Buber (1987, p. 92), existe ainda nele um conteúdo de comunidade natural, incólume e provisoriamente imperturbável, e isso é, vestígio de comunidade primitiva. Vestígio de primitivas comunidades em comunhão, de antigas comunidades rurais. Vestígio de autênticos sentidos de comunidade. E o que resta ainda do autêntico campesinato é parte disso. Por isso, para o professor da escola rural, existe algo concreto a que ele pode referir-se. Se ele assim não o fizer, é sua a decisão.

Entretanto, o que significa, em última análise, que a educação para a comunidade acontece por meio da comunidade? Que é, de fato, educação para a comunidade? Concretamente, em termos pessoais, que é realizado? De que se trata? Que significa dizer de alunos que de indivíduos educados eles se tornam comunidade? Que é educado neles? Que é realizado neles? Que alteração se dá em sua estrutura espiritual e na estrutura de suas relações com o ambiente?

Buber defende (1987, p. 93) que educação é relação, é capacitação. Por esse termo entende-se relação direta, isenta de propósitos, cujo fim é ela mesma, isto é, a capacidade para tal relação com as pessoas com as quais se convive. É para isso que a educação para a comunidade educa. Ela conduz, pois, dos contatos indiretos entre os homens, às relações diretas, dos contatos movidos por interesses para as relações cujo fim são elas mesmas, pois todos os falsos relacionamentos mencionados por Buber não acontecem somente entre os adultos, mas também entre as crianças.

"Voltar-se para o outro" é um dos princípios fundamentais da educação comunitária a que alude o pensamento buberiano, isto é, estabelecer relação autêntica e genuína com o outro.

Para isso é essencial voltar-se para o outro como ele é... para a face vital da outra pessoa com à sua própria face; que dois seres se tornem presentes mutuamente. Este "voltar-se para o outro" eu denominei "dizer-Tu", e é a última exigência. Um homem pode considerar o outro como uma soma de propriedades cognoscíveis, utilizáveis, ou então, ele pode conhecer o outro... reconhecê-lo, experienciá-lo naquele sentido específico, como a relação amorosa que às vezes é descrita como conhecimento. Nesta interação entre seres ele aprende a conhecer o outro não como soma de propriedades, mas como esta pessoa determinada, com um nome, que vive diante dele. Se se toma toda essa soma de propriedades não se tem nada dela, esta voz, esta pessoa. Refiro-me a esta pessoa que se defronta com uma verdadeira pessoa, única, com este nome. Chamá-la pelo nome, endereçar-lhe o "Tu" é voltar-se para esta unicidade. Expresso isso por meio de conceitos porque é algo 
esquecido, perdido. Mas, na verdade, o que quero dizer não é conceitualizável, é profundamente real. É a realidade sobre a qual se fundamenta a autêntica vida comum entre os homens. Tudo o mais não passa de mera aglomeração, um conjunto de indivíduos. Não quero falar dos estágios mais elevados onde se conhece não somente a partir de sua própria situação, mas também a partir da situação do outro (BUBER, 1987, p. 94).

Para Buber, este "voltar-se" recíproco de pessoa a pessoa não é algo que exige esforço ou reflexão; é algo muito simples, a saber: o encontro do ser humano com seus semelhantes.

\section{Educação comunitária e vínculos}

A relação comunitária na educação concerne num vínculo entre professores: comunidade entre os docentes, entre as pessoas que devem realizar esta obra mais difícil e mais séria de nosso tempo. É um verdadeiro elo entre pessoas.

Em segundo lugar: a relação comunitária entre professores e alunos: que o professor esteja relacionado com o aluno com o espírito comunitário para o qual ele quer educá-lo. De outro modo, afirma Buber, ele não poderá fazê-lo se o aluno - naqueles momentos calmos e não em instantes agitados - não o sentir como o professor, se o aluno não perceber sem cessar (murmurando): "sim é isso". Assim a relação comunitária ocorre. Isso surge a partir deste fundamento, a saber, quando o professor tem o senso natural de comunidade, de acordo com o seu ser, e o transmite a seu aluno, então ela surge, só então ela se irradia (1987, p. 95).

Outra importante perspectiva de Buber, que intervém na organização da escola, é a interação entre as classes etárias. Algumas escolas procuram solucionar isso, introduzindo aulas comuns. É importante encontrar uma possibilidade de se estabelecer um contato com as classes de alunos de maior idade, assim elas teriam de realmente construir os interesses da vida para permutar. Isso, porém, deveria ser tarefa dos professores, dos educadores, daquelas pessoas que trabalham na escola.

Outra questão destacada é muito particular e própria do período em que Buber realizou a conferência sobre educação: uma real interação entre os gêneros.

Muitas pessoas que lidam com isso, encaram a questão de tal maneira que, de fato, tratam as meninas como se fossem meninos. É importante que as crianças de ambos os sexos sejam educadas juntas (...) que haja uma verdadeira relação entre as pessoas que se desenvolvem de diversas maneiras, precisamente pela sua diversidade. De mesmo modo, é extremamente importante que, hoje, as pessoas com cinquenta anos de idade se entretenham com as de vinte, não com ar de condescendência, mas que se relacionem com elas livremente, sem reservas, revelando-se elas... (1987, p. 96) 
Buber também destaca que a escola deve estar relacionada com a sociedade tal como é e, cabe à escola, preparar os alunos para conhecer a sociedade e inserir-se nela com algo que deve ser penetrado com conteúdo de comunidade. As diversas instituições da sociedade devem ser conhecidas como são formadas em sua receptividade, isto é, cada segmento da sociedade é considerado carente de comunidade, que necessita de comunidade e como algo que pode ser realizado com a comunidade.

Outro aspecto amplamente realçado por Buber refere-se à relação da escola com o lar. As escolas públicas possuem uma instituição que até hoje não se tornou plenamente ativa, afirma Buber, embora exista aqui e acolá. “Terá, no entanto, enorme força no futuro”. Tratase dos "conselhos de pais".

Há lugares onde existem realmente os conselhos de pais, isto é, uma comunidade de certo tipo, onde os pais se relacionam mutuamente, e não se limitando cada mãe falar de seu próprio filho, mas onde cada um se preocupe com o outro, formando um verdadeiro grupo coeso, onde os pais se encontram com os professores e com estes tratam de assuntos comuns. Devo mencionar que tais "conselhos de pais" são mais frequentes em meios proletários do que em meios burgueses. O proletariado tem esta capacidade do contato solidário, de união de interesses, do tratamento comum. Em meios burgueses isso é muito raro. A escola, penso eu, ou talvez os professores, deveriam atribuir-se a tarefa de levar a questão da comunidade para os lares, atrair lares para a obra, para o trabalho educacional na comunidade. Embora isso seja difícil, não é impossível. Não esqueço por um momento que é difícil exigir tudo isso do professor, tomado já por seus próprios deveres. Sei o quão difícil é para ele cumprir as tarefas exteriores e - digo isso com coração pesado - não conheço outro caminho. Não conheço outra pessoa que pudesse realizar esta obra. Esta tarefa deveria ser levada também para o seio das famílias. Diria mesmo que deveriam colaborar na construção da família, pois os "conselhos de pais" iriam de sua parte influenciar a família (BUBER, 1987, p. 97).

Buber também indaga sobre as questões estritamente relacionadas ao ensino, havendo, portanto, domínios em que é possível a formação do conhecimento sobre a comunidade. Por exemplo: a história. Buber afirma que essa disciplina pode ser ensinada não como a história do Estado. Ao contrário,

quando se ensinar história, dever-se-ia partir da questão: quantas comunidades em certa época, foram destruídas entre os homens? Como, de que modo, com que dificuldades, sob que resistências estas batalhas subterrâneas - que são expressivamente mais importantes para a humanidade do que as batalhas abertas, visíveis, sobre as quais, aliás, se tem falado tanto - aconteceram? Refiro-me a batalha empreendida pela humanidade em se tornar uma comunidade. Creio que a história pode ser ensinada assim (1987, p. 98). 
Buber também avalia a necessidade de outros modos de ensino de línguas, em que a língua seja ensinada como uma verdadeira fala entre os homens, um tipo peculiar do falar, relações pessoais que aí são expressas e que são influenciadas pela língua.

Como as relações humanas são influenciadas pela língua? (...) É necessário tomar a língua como fala, como uma realidade que acontece e abrir todo este, por assim dizer, herbário de línguas que podem ser ensinadas, e dizer como que cada planta, onde vive e cresce - do mesmo modo a "elocução" desta palavra e a história desta "elocução". É mais importante aprender 20 palavras desta natureza do que 500 de qualquer outra... (1987, p. 98).

Em todo o ensino, propõe Buber, é muito mais importante que se evidencie o seu conteúdo de comunidade. Em outras palavras, do fato de o professor ensinar comunidade de modo comunitário, "comunialmente", ou, "então, que ele faça, acima de tudo, aquilo que é o alfa de toda a educação, o contexto educacional que ao invés de ser uma tarefa que o professor se impõe é algo que ele revela” (1987, p. 99).

Nenhuma comunidade pode existir sem isso, assevera Buber. Sem dúvida o professor deve encontrar-se realmente com o aluno, deve dar-lhe o que tem, assim como a gente encontra o outro no Tu, oferecer-se ao outro sem, no entanto, impor-se a ele, revelar-se a ele estando disponível. Este tipo de encontro é a vida humana.

E, por último, Buber destaca, ainda que brevemente, as várias maneiras de os professores e os alunos estarem juntos: jogos, música. São diversas maneiras de convivência que não têm outro objetivo senão a tensão que é a própria essência do conviver. O ensino jamais pode ser despojado de finalidade, uma vez que as pessoas se congregam todas aí justamente para esta finalidade. O jogo, porém, assim como a música, é algo diferente, é descanso, propõe Buber.

Todavia, este sentimento no jogo ou na música, de ser parte de uma multidão pela qual é conduzido de modo que permita integrar-se a outrem, é uma tentação estética. Por exemplo, se as crianças fazem músicas juntas, ou então, se em uma escola se formou um quarteto, e então ensaiam juntas, é sumamente importante que cada um dos membros conheçam a contribuição dos outros integrantes, isto é, que cada um observe o que o outro deve fazer, e que ele próprio não faz; que observe o outro, perceba sua contribuição, que estabeleça relações nesta comunidade. E, dessa forma, o educar-educando possa e deva influenciar algo assim, introduzir isso nessa organização estética. Ele pode conduzir a relação direta, tanto quanto é possível nesta situação. Pode conduzir do sentimento de se ter uma comunidade para a realização da comunidade, para o estabelecimento da comunidade, para o entrar em comunidade (1987, p. 100). 
Da conferência de 1929, é imprescindível destacar o inolvidável compromisso de Buber para com uma nova perspectiva para a escola e o educar a partir da comunidade e do princípio dialógico. A finalidade da educação no pensamento buberiano é o compromisso com a formação de seres capazes de estabelecer relações autênticas com o outro. Isso pressupõe, como analisa Maria Betânia do Nascimento Santiago, a superação de uma visão meramente adaptativa dos indivíduos às exigências sociais, e que se assuma como condição básica para educar: a formação de uma consciência unificada, capaz de lidar com as situações singulares da realidade, buscando, na medida do possível, estender a própria experiência de comunidade para as esferas sociais. A definição, ao mesmo tempo em que nos deixa entrever o sentido da educação, também caracteriza a relação, enquanto núcleo essencial da comunidade e do educativo. A relação na comunidade é, desse modo, o meio e o fim, o telos do processo educativo (SANTIAGO, 2008, p. 311-312). É a relação dialógica de um Eu em Tu, como possibilidade do autêntico e genuíno vínculo com o outro, a quem nos dirigimos, voltando-se para ele como ele é, assumindo-o em sua totalidade.

\section{Considerações finais}

Para isso é essencial voltar-se para o outro como ele é... para a face vital da outra pessoa como à sua própria face; que dois seres se tornem presentes mutuamente. Este "voltar-se para o outro" eu denominei "dizer-Tu", e é a última exigência (BUBER, 1987, p. 94).

A história e o pensamento filosófico de Buber são marcados por grande confiança no humano. Com essa convicção, dedicou sua vida e sua obra almejando que as pessoas vivessem entre si, o mais profundamente possível, a sua humanidade, por meio de autênticas relações dialógicas, o inter-humano: a autenticidade, a presença, a abertura e a conversação genuína (PEREIRA, 2013, p. 2).

Não há existência sem relação e diálogo, esta é a principal ideia de Buber elucidada em sua filosofia. As palavras-princípio, Eu-Tu (relação), Eu-Isso (experiência), demonstram duas dimensões da filosofia do diálogo que, segundo Buber, dizem respeito à própria existência. Segundo Zuben, "a concepção buberiana do diálogo é atípica porque se recusa a tratá-lo como simples processo psicológico ou mero meio de comunicação" (2003, p. 167).

O diálogo autêntico indica o verdadeiro voltar-se-para-o-outro, o que confere a esse evento uma categoria de atitude do homem frente ao mundo manifestando-se na palavra 
proferida que "é pronunciada na linguagem da ação" (BUBER, 1974, p. 4). O ser humano é inerentemente relacional.

O protesto lançado por Buber contra a despersonificação ou contra a coisificação, a que foi submetido o homem moderno através da supremacia do Eu-Isso em detrimento da autêntica relação, serve de certo modo, como pano de fundo para a tentativa de transformação para a verdadeira comunidade (ZUBEN, 2003, p. 129).

O sentido da educação é contribuir para a edificação da vida em comunidade. $\mathrm{Na}$ relação educativa, o professor assume um lugar significativamente importante: a formação dos caráteres que irão constituir a nova comunidade, cuja finalidade é a verdadeira Vida, a legítima relação inter-humana, isenta de quaisquer interesses que não sejam uma vida vivida comunitariamente.

Compreender o humano como ser de relação significa a impossibilidade de vê-lo isoladamente. É na vida comunitária que este homem realiza seu modo próprio de ser. A posição assumida por Buber revela a necessária conversão do indivíduo, com vistas à regeneração das comunidades, naquilo que se constitui sua força viva. Buber estava convencido de que a consecução de tal projeto social não poderia ser realizada por qualquer concepção de educação, por isso se propõe a rever o projeto educativo que se estruturou no mundo moderno, e a pensar numa educação endereçada para a comunidade (SANTIAGO, 2008, p. 332). A visão de comunidade proposta evoca uma profunda compreensão do significado da alteridade no âmbito das experiências coletivas, que não devem se dissolver na massa do universalismo político.

A defesa do diálogo entre $\mathrm{Eu}$ e Tu se apresenta em diferentes elaborações como condição fundamental à existência humana e à vivência educativa. Nela se faz necessário e urgente o encontro.

Buber compreende a educação como postura essencial do educador, como ser responsável pelo mundo e pelo outro. O engajamento pessoal com o outro, o educando, é a condição fundamental para a realização do educativo. O caráter essencialmente pessoal da relação educativa evidencia a responsabilidade daqueles que assumem essa obra. Ela não é uma simples tarefa, mas uma existência colocada como referência para aqueles que se encontram em formação. O educador é um representante-responsável pelo aluno e pelo mundo, o qual irá enxergar por meio das ações deles. A possibilidade de educar alguém está na existência concreta. 
A confiança é a verdadeira dimensão do educativo, que se institui no diálogo autêntico e requer daquele que educa essa postura. Apenas numa espontânea confiança é possível a abertura e, com isso, a formação. Por isso, Buber se refere à espontaneidade como fator preponderante na educação, uma vez que o real alcance do educador em relação aos seus alunos pressupõe a presença. O espontâneo como face do dialógico não é uma opção metodológica, mas uma postura essencial.

Aquele que educa deseja atuar sobre o educando. Contudo, o seu atuar não é da mesma ordem daquele que pretende propagar ideias. Vivendo num mundo de indivíduos, o educador reconhece a si mesmo como um auxiliar das forças atualizadoras dessa individualidade, assumindo a luta contra aquelas forças que impedem o desabrochar do humano, como sujeito a contradições.

O diálogo é a própria essência do educativo, e não uma simples estratégia pedagógica. Nessa perspectiva, a interligação, a relação, torna-se central ao projeto formativo de Buber, que situa no diálogo a possibilidade da realização do humano.

\section{REFERÊNCIAS BIBLIOGRÁFICAS}

BUBER, Martin. Caminos de utopía. Tradução de J. Rovira Armengol. México: Fondo de Cultura Econômica, 1987.

BUBER, Martin. Eu e Tu. Tradução de Newton Aquiles von Zuben. São Paulo: Cortez e Moraes, 1977.

BUBER, Martin. O socialismo utópico. 2. ed. Tradução de Pola Civelli. São Paulo: Perspectiva, 2005.

BUBER, Martin. Sobre comunidade. Tradução de Newton Aquiles von Zuben. São Paulo: Perspectiva, 1987.

SANTIAGO, Maria Betânia do Nascimento. Diálogo e educação: o pensamento pedagógico de Martin Buber. 2008. Tese (Doutorado em Educação) - Universidade Federal de Pernambuco, Pernambuco.

ZUBEN, Newton Aquiles von. Martin Buber: cumplicidade e diálogo. Bauru: EDUSC, 2003. ZUBEN, Newton Aquiles von. Martin Buber e a nostalgia de um mundo novo. In: BUBER, Martin. Eu e tu. São Paulo: Cortez e Moraes, 1977. 


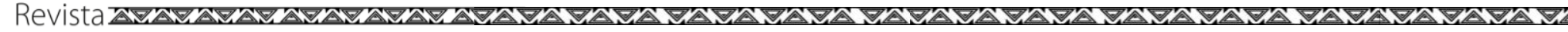

ZUBEN, Newton Aquiles von. Posfácio. In: BUBER, Martin. Sobre comunidade. São Paulo: Perspectiva, 1987.

Artigo recebido em: 27/06/20

Artigo aprovado em: 04/10/20 